\title{
Treatment of Post Burn Scar Extended Deformity of the Toes IV Degree and Using Bridge Cellular Cutaneous Flap
}

\author{
Babur M. Shakirov", Ysuf M. Ahmedov, Sanoat H. Zohidova, Erkin A. Hakimov, Komil R. Tagaev
}

Samarkand State Medical Institute, Burn Department of RSCUMA and Inter-Regional Burn Center, Samarkand, Uzbekistan. Email: *baburshakirov@yahoo.com

Received April $2^{\text {nd }}, 2013$; revised May $4^{\text {th }}, 2013$; accepted May $12^{\text {th }}, 2013$

Copyright (C) 2013 Babur M. Shakirov et al. This is an open access article distributed under the Creative Commons Attribution License, which permits unrestricted use, distribution, and reproduction in any medium, provided the original work is properly cited.

\begin{abstract}
Post burn dorsal foot contractures of the toes of the IV degree cause functional limitations of all lower extremities, which creates a serious cosmetic defect, and therefore, needs surgical reconstruction. The series of 11 patients ( 7 men and 4 women) with extended contracture of the 4th degree of toes after burn were operated upon by using the new method with the flap including subcutaneous tissue (bridge-like stem), and the operations were performed at Samarkand Burn Center, Samarkand, Uzbekistan. We observed a good result with no complications. The flap was viable, and its sensibility was preserved. No marginal necrosis was noticed. As a result, the use of this method allowed achieving normal aesthetic outlines. The flap acquired the properties of the healthy skin without contracture. For the whole operated feet, it is important to wear pressure socks as soon as the wounds are fully healed and to continue this pressing therapy until the edema and recurrence of contracture are no longer being the problems. This usually means a period of 6 to 9 months.
\end{abstract}

Keywords: Burns; Foot; Post Burn Dorsal Flexion Contracture and Surgical Treatment

\section{Introduction}

Post burn contractures are distressingly common and severe in developing nations and are significant problems in developed countries as well.

Post burn dorsal foot contractures of the toes IV degree cause functional limitations of all lower extremities, which creates a serious cosmetic defect, and therefore, needs surgical reconstruction

Contractures after burn injury are liable to occur when the burn has been deep or not properly treated. The post burn dorsum contracture deformities of feet present the complex specific pathology of bearing-motor apparatus developing as complications after serious burn of feet dorsum surface. The foot is prone to develop into dorsal contractures after burn injuries: the skin over the dorsum of the foot looses, and the movements of the MP joints are more concentrated around dorsiflexion than plantar flexion [1-7].

Dorsal contracture of foot may be with the spread of scars on toes and formation of extension contractures of metatarsophalangeal joints involving ankle joint or without it [8].

The first one is used in deformation of the dorsum of

"Corresponding author. foot, the second in bearing of bones, joints, necessity of elimination of tissue. It may be the skin with insignificant changes, earlier transplants or being placated and tissue reserve on width.

Clinical course of so-called sandal burns is of particular attention $[9,10]$. Sandal burns are characterized by such severe deep injuries because of a close contact of the body with live coals or woods including not only skin injuries of various depths but also injuries of underlying tissues: subcutaneous fat, fasciae, muscles, and even bones.

Burn contractures, especially severe ones, have a tendency to recur without adequate intra- and postoperative care [11].

In particular, there is little information concerning the most effective methods of elimination of post burn extension deformation of toes IV degree.

\section{Material and Methods}

The series of 11 patients ( 7 men and 4 women) with extension contracture of 4 th degree of toes after burn were operated upon using the new method flap included subcutaneous tissue (bridge-like stem) performed at Samarkand Burn Center, Samarkand, Uzbekistan. The causes 
were: sandal burns (6 patients), sulfuric acid burns (2 patients), and flame (3 patients).

4 patients had burns 5 years ago and the others more than 5 years. There was re-extension of metatarsal-phalangeal joints from $100^{\circ}$ to $150^{\circ}$ in all observations. 7 out of 9 patients' scars had the form of scarry tightening dispersing like a fan from the centre of the dorsum of foot to every toe.

\subsection{The Operation Technique}

Dorsal contractures of the foot limit plantar flexion. Practice has shown that in extension contractures of toes of the 4th degree with complete dislocation on the side of the plantar surface on the level of metatarsal-phalangeal joints and there is stretching and redundancy of soft tissues occurred including skin with subcutaneous tissue swelling like a roller (Figure 1(a)).

Developing reserve of tissues 2.5 - $4.0 \mathrm{~cm}$ wide is like extension of tissues strip going from the inner surface of I to the external surface of $\mathrm{V}$ metatarsal bone (Figures 1(b)-(d)). Taking into consideration this condition, we cut out a strip of skin including subcutaneous tissues in transverse direction to the foot with nutrient pedicles on the level of metatarsal-phalange joints (Figure 1(e)). Skin adipose strip was transferred above the toes on the dorsal surface of the food and was applied in transverse direction, closing the area of the metatarsal-phalange joints. The wound on the plantar surface was sutured without tightening. Nutrition of a bridge-like stem of this kind was carried out due to corresponding arteries of I and $\mathrm{V}$ toes. The ratio of width to length of this stem was 1:4. The rest of the wound was closed by means of free skin transplantation (Figure 1(f)).

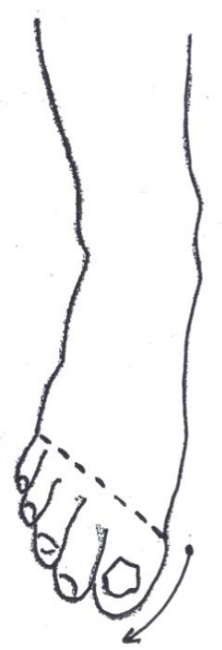

(a)

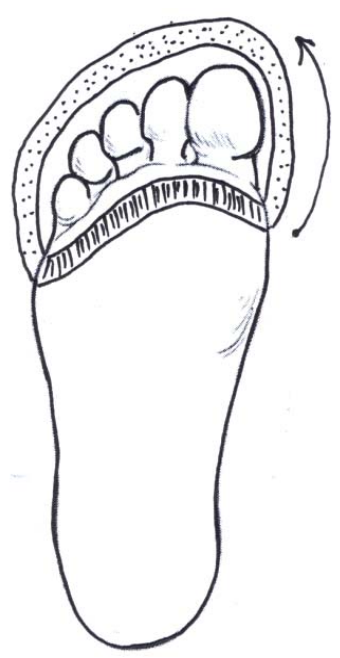

(d)

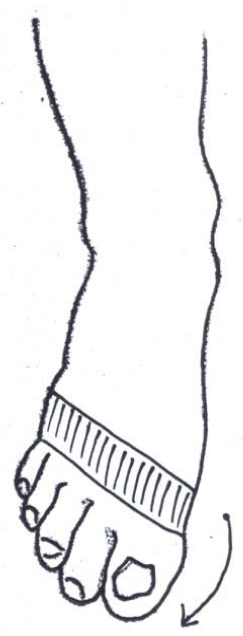

(b)

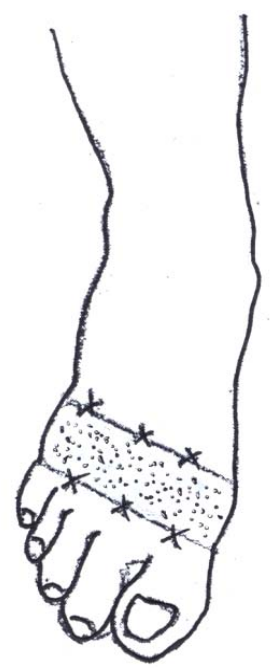

(e)

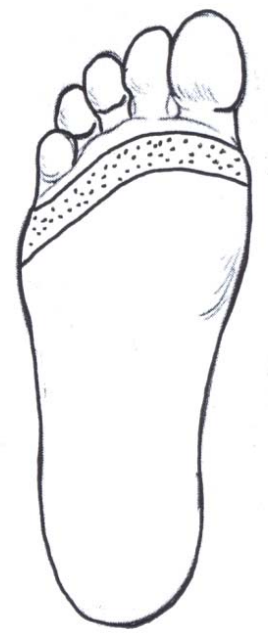

(c)

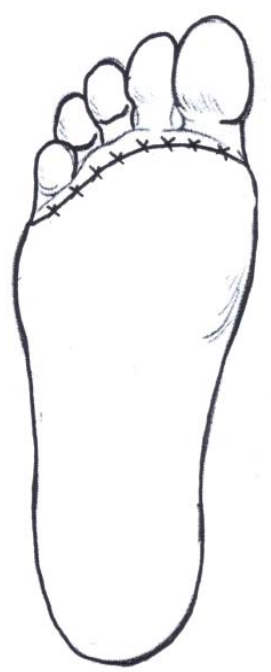

(f)

Figure 1. Scheme of the treatment of post burn scar extended deformity of the toes IV degree and using bridge cellular cutaneous flap. 


\subsection{Patient}

A 16-year-old man had a dorsal contracture involving the right foot which disturbed range of motion of all the toes as a result of scar contracture. From his anamnesis it was established that he had sandal burns at the age of 2 years. He was treated in Inter-Regional Burn Centre for 28 days where skin transplantation in the area of dorsal surface of the right foot was performed. 11 years ago repeated operation for extended contracture of all toes of the right foot where free-skin transplantation was performed. At present the patient developed extension contracture of all toes of the right foot again and he appealed to Burn Centre (Figure 2).

\section{Results}

We observed a good result with no complications. The
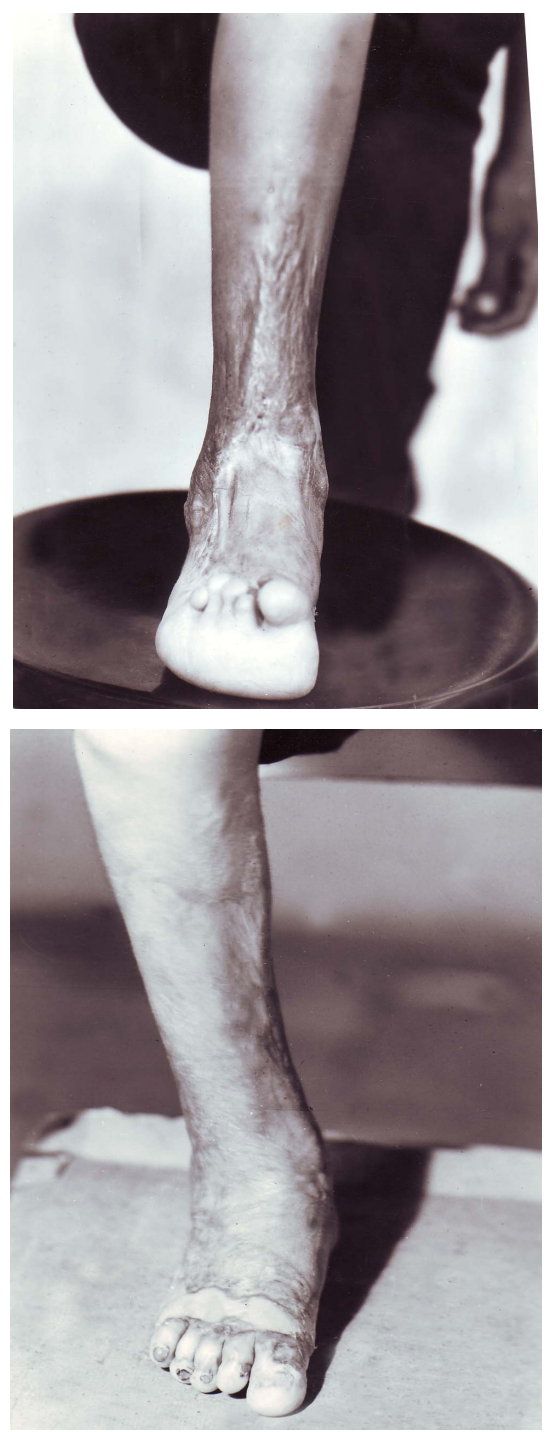

Figure 2. Pre-operative scar contracture and the result after surgery. grafts were viable, and their sensibility was preserved. As a result, the use of this method allowed achieving normal aesthetic outlines.

In the evaluation of the follow-up results of the operative treatment we considered it to be a good result if the patient had no disturbances. The extremity was correct in form and the flap was similar to normal healthy skin. The result was considered to be satisfactory if the form and functions of the extremities were considerably improved, but physiotherapeutic treatment or some small additional operations were necessary.

The follow-up results from one to four years were good for all patients. The flaps acquired the properties of the healthy skin without contracture. Patients can take up their work in 2.0 - 2.5 months after surgery.

\section{Discussion}

The high percentage of patients who underwent the post burn reconstructive surgical treatment indicates the poor effectiveness of conservative methods of therapy used today [12].

Scars may be soft particularly in presence of transplants with protruding tightening going to each toe or are presented as a thick, rough mass luxating the foot. Depending on the spread of scars, there thickness in plicae and also the degree of contracture, free or combined plastics is performed.

Until recently classic methods of local skin plastics are applied. However, transference of scarry triangle flaps is often (to 30\%) accompanied by their necrosis and leads to negative results.

In spite of preference to local skin plastics, there are indications for free skin plastics. Until present there are contradictions concerning transplants to be used: fulllayered or splitted. A combined skin plastic has clear indications and advantage in comparison with free skin plastics.

If it is impossible to close wound defect completely by local tissues, local skin plastics should be applied with additional free skin transplantation. On the other hand, in application of free skin plastics it is necessary to take into consideration the following: whether it is possible to close functionally active areas by local tissues and the rest wounds on inactive areas by free skin transplants. In elimination of long existing extension contractures of toes, local skin plastics has advantage since the defect after scars dissection is replaced by local tissues alake in their features.

For all operated feet, it is important to wear pressure socks as soon as the wound are fully healed and to continue this pressure therapy until edema and recurrence of contracture are no longer problems. This usually means a period of 6 to 9 months. 
The main role has to be played by rehabilitation centres where all methods of treatment are available.

\section{REFERENCES}

[1] V. M. Grishkevich, H. B. Myatiev, V. Y. Moroz, et al., "Surgical Treatment of Post Burn Deformations of Dorsum of Foot and Ankle Joint,” Surgery, Vol. 11, 1986, pp. 113-117.

[2] P. C. Leung and J. C. Cheng, "Burn Contractures of the Foot,” Foot \& Ankle International, Vol. 6, No. 6, 1986, pp. 289-294. doi:10.1177/107110078600600602

[3] I. Feller and W. Crabb, "Reconstruction and Rehabilitation of Burned Patient," National Institute for Burn Medicine, Ann Arbor, 1979, p. 423.

[4] B. M. Mirazimov, B. S. Tursunov and V. M. Grishkevich, "Postburn Deformations of Extremities in Children," Ibn Sino Publishing House, Tashkent, 1991, p. 342.

[5] B. Erdogan, M. Gorgu, O. Girgin, T. Akoz and O. Deren, "Application of External Fixators in Major Foot Contractures," The Journal of Foot and Ankle Surgery, Vol. 35, No. 3, 1996, pp. 218-221. doi:10.1016/S1067-2516(96)80100-1

[6] S. Guild, "A New Splinting Approach for Dorsal Foot Burns," The Journal of Burn Care \& Rehabilitation, Vol.
22, No. 6, 2001, pp. 454-456. doi:10.1097/00004630-200111000-00018

[7] B. M. Shakirov and B. S. Tursunov, "Treatment of Severe Foot Burns in Children,” Burns, Vol. 31, No. 7, 2005, pp. 901-905.

[8] N. A. Kurinny, A. A. Romanenko and S. B. Bogdanov, "Surgical Treatment of Post Burn Deformations of Dorsum of Foot and Ankle Joint in Children," Combustiology on the Border of Ages, Materials of International Congress, Moscow, 9-12 October 2000, pp. 196-197.

[9] B. M. Shakirov, "Sandal Burns and Their Treatment in children," The Journal of Burn Care \& Rehabilitation, Vol. 25, No. 6, 2004, pp. 501-505. doi:10.1097/01.BCR.0000144526.71143.DE

[10] B. M. Shakirov, "Evaluation of Different Surgical Techniques Used for Correction of Post Burn Contracture of Foot and Ankle," Annals of Burns and Fire Disasters, Vol. 23, No. 3, 2010, pp. 137-143.

[11] B. M. Shakirov, "Special Issue: About Scar Deformities of the Foot," Journal of Wound Technology, January 2012, pp. 77-78.

[12] Y. Lee, K. Minn and R. M. Baek, "A New Surgical Treatment of Keloid: Keloid Core Excision,” Annals of Plastic Surgery, Vol. 46, No. 2, 2001, pp. 135-140. doi:10.1097/00000637-200102000-00008 